\title{
Natureza da Ciência (NOS): para além do consenso
}

\section{Nature of Science (NOS): Beyond the "Consensus View"}

\author{
Nelson Rui Ribas Bejarano ${ }^{1}$ \\ https://orcid.org/0000-0001-5496-1315 \\ Agustín Aduriz-Bravo ${ }^{2}$ \\ https:// orcid.org/0000-0002-8200-777X \\ Carolina Santos Bonfim ${ }^{1}$ \\ https://orcid.org/0000-0001-8271-4098
}

\begin{abstract}
Resumo: O objetivo deste artigo é discutir a importância da NOS (Nature of Science) na formação dos professores de ciências e no ensino de ciências em geral. Há uma centralidade acerca dessa discussão, desde que se admite que saber sobre ciência é tão importante quanto saber conteúdos de ciência. Assumimos que a NOS é um conjunto de saberes ou "olhares" metateóricos que trata das várias características da ciência, seja do ponto de vista internalista, seja em seu caráter eminentemente cultural e social. Encontramos em Douglas Allchin e em Derek Hodson argumentos que sustentam o uso da Whole Science em detrimento do uso de listas consensuais, muito mais comuns na formação de professores e no ensino de ciências. Por fim, trazemos um exemplo de uso da Whole Science na forma de uma história ficcional, na qual vários pontos da NOS podem ser explorados para efeitos de seu ensino.
\end{abstract}

Palavras-chave: Natureza da ciência. Formação de professores. Ensino de ciências.

\begin{abstract}
This article aims to discuss the importance of NOS (Nature of Science) in the training of science teachers and science teaching in general. This is a pivotal discussion because it is assumed that knowing about science is as important as knowing the contents of science. We understand, from the outset, that NOS is a set of meta-theoretical knowledge or "views" that deal with the various characteristics of science, either from the internal point of view (its methods and its theories) or its eminently cultural and social character. After all, which NOS points are essential for teacher training? We found arguments in Allchin and Hodson that support the use of Whole Science rather than consensus lists, which are much more common in teacher education and science teaching. Finally, we present an example of Whole Science use in the form of a fictional story, in which many points of NOS can be explored in teaching.
\end{abstract}

Keywords: Nature of science. Science education. Teacher training.

\footnotetext{
${ }^{1}$ Universidade Federal da Bahia (UFBA), Instituto de Química, Salvador, BA, Brasil. E-mail: bejarano@ufba.br

${ }^{2}$ Universidad de Buenos Aires (UBA), Facultad de Ciencias Exactas y Naturales, Centro de Formación e Investigación en Enseñanza de las Ciencias (CeFIEC), Buenos Aires, Argentina.
} 
Bejarano, N. R. R.; Aduriz-Bravo, A.; Bonfim, C. S.

\section{Introdução}

A discussão em torno da NOS (Nature of Science), em português "Natureza da Ciência" e de seu valor educativo vem de longa data. Como nos informa Matthews (2012), em 1854, William Whewell, cientista inglês, proferiu uma palestra na Royal Institution da Grã-Bretanha, na qual sua mensagem apontava a relação entre o desenvolvimento histórico da Ciência e a educação científica. Há outro nome emblemático na valorização do estudo da natureza da ciência, James Bryant Conant, que defendeu de forma explícita e sistemática a articulação entre o ensino de ciências e as contribuições da História e Filosofia da Ciência (CONANT et al., 1957) e, por isso, pode ser considerado um dos pioneiros em argumentar amplamente que estudar ciência de maneira informada pela Filosofia e a História da Ciência torna o ensino daquela muito mais significativo.

Vários outros nomes bem conhecidos perceberam o potencial da "reaproximação" entre Ensino de Ciências e História e Filosofia da Ciência, aglutinados agora sob a noção de NOS. Por exemplo, James Rutherford, que há 50 anos publicava um artigo que tratava de separar o que era investigação dentro do empreendimento científico e o que era investigação para efeitos de aprender conceitos e métodos da ciência. O interessante também na contribuição de J. Rutherford para a discussão em torno da NOS é o fato de ele ter sido um dos criadores do Projeto 2061 no âmbito da American Association for the Advancement of Science (AAAS), um projeto que talvez seja o maior esforço de longo termo para a melhoria do ensino de ciências e de alfabetização científica de todos os tempos.

Dentre outros nomes importantes que poderiam ser citados nesse conjunto de pessoas que acreditaram e seguem acreditando na importância de se aprender sobre a NOS, além de conteúdos da ciência e de seus processos e habilidades, citaremos apenas mais um: Michael R. Matthews. Colocamos o nome de Matthews por sua incansável batalha pela produção e difusão de conhecimentos no campo de pesquisa conhecido como History, Philosophy and Sociology of Science and Science Education (HPS) organizado em torno do International History, Philosophy, and Science Teaching Group (IHPST) formado em 1987. Matthews foi também o primeiro editor da principal revista de HPS, a Science \& Education.

A preocupação com aspectos diversos da NOS mobiliza grandemente a comunidade de pesquisadores em ensino de ciências na atualidade. Isso pode ser verificado rapidamente através dos trabalhos apresentados nos últimos encontros internacionais do IHPST, ocorridos nas cidades do Rio de Janeiro, em 2015, e Ancara, em 2017. Em cada um desses eventos, foram apresentados mais de 20 trabalhos que tratam diretamente da problemática da NOS.

Como consequência, este artigo sustenta que os estudos sobre a ciência têm ganhado cada vez mais relevância no âmbito das salas de aula de ciências dos diferentes níveis educacionais. A concepção atual de uma pessoa cientificamente alfabetiz̧ada não é somente a de alguém que sabe conteúdos da ciência, mas também e, sobretudo, que sabe sobre sua natureza (produção, evolução, avaliação, difusão, relações com o contexto), sendo a NOS compreendida aqui como um conjunto de saberes ou olhares metateóricos que trata dos vários aspectos da atividade científica, seja do ponto de vista internalista (seus métodos e suas teorias), seja em seu caráter eminentemente cultural e social. 


\section{As listas consensuais}

O aparecimento de listas consensuais de itens de NOS, que seriam relevantes para o ensino, deriva em grande parte da visão de educadores científicos que acreditam que a reflexão sustentada sobre alguns aspectos do empreendimento científico deveria ser introduzida nas salas de aula. Sem dúvida, há uma aparente contradição em falar em listas consensuais, já que nos dias de hoje há numerosas e diversas listas disponíveis. Devemos entender, então, que a intenção dos pesquisadores que acreditam que haja consenso em termos da NOS é de constantemente interagir entre si buscando de fato uma única lista consensual final mínima, sobre a qual apareçam pequenas variações para os distintos contextos e finalidades.

Com o atraente título de "Revisión de consensos sobre naturaleza de la ciencia" (MARÍN; BENARROCH; NIAZ, 2013), os autores estudam cinco artigos que, segundo a metodologia adotada, seriam representativos do trabalho dos grupos de pesquisa que apoiam a chamada consensus view em torno da NOS. Esses artigos analisados (FERNÁNDEZ et al., 2002; LEDERMAN et al., 2002; MCCOMAS; OLSON, 1998; OSBORNE et al., 2003; VÁZQUEZ et al., 2001) apresentam como produto uma lista de NOS. A revisão de Marín resume a análise dos cinco artigos clássicos em três tabelas. A primeira seleciona publicações dos grupos de pesquisa que trabalham com listas de consenso da natureza da ciência. Aparecem os grupos e suas proposições: o grupo de William McComas (Estados Unidos) propõe 16 itens que comporiam a sua lista; o grupo de Norman Lederman (Estados Unidos), oito proposições; o grupo de Jonathan Osborne (Reino Unido), dez proposições; o grupo de Daniel Gil-Pérez (Espanha), sete proposições, e o grupo de José Antonio Acevedo-Díaz (Espanha), 16 proposições. A contribuição maior do artigo de revisão de Marín et al. (2013) é ter encontrado uma metodologia que pudesse reduzir ou agrupar essas 57 proposições ou itens de NOS, todos alegadamente consensuais, em um único sistema que pudesse ser, no mínimo, prático para os objetivos a que se destinam essas listas.

Na segunda tabela, chamada pelos autores de contextos, já se observa uma redução em relação à primeira tabela. Aparecem os contextos: (1) de surgimento e aplicação da ciência (apoiado nas ideias CTS), com quatro proposições; (2) da fase privada (atividade em fase de descobrimento), com duas proposições; (3) de interação privado-pública, com duas proposições; e, finalmente, (4) da fase de justificação, com quatro proposições. Das 57 proposições originais, têm-se na segunda tabela apenas 12 proposições, candidatas a itens de uma possível lista consensual unida. Por fim, na terceira tabela, que os autores chamam de sistematização dos contextos, aparecem os mesmos contextos enunciados na segunda, porém agora na forma de questões e respostas às questões. De maneira que no primeiro contexto (surgimento e aplicação) surgem quatro questões e três respostas vindas dos cinco grupos de pesquisa escolhidos para a revisão. No segundo contexto (fase privada), surgem duas questões e três respostas. No terceiro contexto (interação privado-pública), duas questões e três respostas. E, finalmente, na fase de justificação, quatro questões e 14 respostas. Estaria pronta, dessa forma, mais uma lista das muitas que circulam pela literatura reivindicando a primazia de serem incluídas junto aos currículos nacionais de ensino de ciências e aos programas nacionais de formação de professores.

Há uma curiosa conclusão - entre outras- que chegam os autores desse artigo de revisão: 
[...] em relação à NOS, corrobora-se que existem importantes consensos em uma diversidade de contextos em que se desenvolve a atividade científica, o que possivelmente se deva à intensa interação entre especialistas acerca da NOS, realizada através das mesmas publicações ou em foros e reuniões especializadas (MARÍN et al., 2013, p. 136, tradução nossa).

Em torno dessa produção de consensos diversos, uma pergunta interessante seria: em que momento e como a Ciência e a Filosofia da Ciência contribuem para a elaboração dessas listas? Essa observação sugere mais que se procura um acordo entre os educadores em ciências, na busca da lista "final", do que um olhar mais profundo sobre as características da própria atividade científica que desejam, através dessas listas, entender e adotar para as aulas de ciências.

Em nossa revisão, dentro dos artigos defensores do consenso encontramos também o de Vázquez-Alonzo et al. (2008), que caminha por argumentos em busca de consensos. O de Michael Clough (CLOUGH, 2007), que aborda a questão do consenso - via tenets - se apoiando, entre outros autores, em Abd-El-Khalick, Bell e Lederman (1998, p. 418, tradução nossa): "as discordâncias que continuam a existir entre filósofos, historiadores e educadores da ciência são demasiadamente abstratas para estudantes do K-12 compreenderem [...] e demasiadamente esotéricas para ter consequências imediatas em suas vidas cotidianas". Na realidade, esse artigo propõe que os tenets se transformem de afirmações para questões, mantendo a ideia do consenso no interior da comunidade de pesquisa em Ensino de Ciências.

Há também um interessante estudo de Matthews (2012), que parte de uma das listas de consenso do grupo de Lederman. O autor, inicialmente, faz críticas severas à posição filosófica vacilante de Lederman: é um realista ou um pragmático? Por fim, acaba tomando a lista de sete elementos de Lederman, acrescenta mais alguns pontos e propõe que se troque o nome de NOS para FOS (Features of Science), que considera mais adequado porque o termo features é mais "relaxado, contextual e heterogêneo" (MATTHEWS, 2012, p. 4, tradução nossa). Os artigos elencados pela revisão de Marín, Benarroch e Niaz (2013) compreendem, em grande medida, o estado da arte sobre o debate acerca do que se denomina consensus view.

\section{A falta de consenso sobre as listas consensuais}

Dentro do próprio campo dos consensualistas encontram-se argumentos para que se questione a validade dos processos de construção das chamadas listas consensuais, assim como dos resultados obtidos. O capítulo de livro de Matthews (2012), por exemplo, pretende assinalar algumas inconsistências nas listas consensuais proferidas pelo grupo de Lederman (especialmente em LEDERMAN, 1992, 2004). O foco das críticas de Matthews são aos chamados Lederman Seven, a lista de NOS que contém sete pontos (LEDERMAN, 2004). Matthews alerta para os pontos positivos (presença de discussões sobre a NOS nas salas de aula entre outras coisas), porém, também para os aspectos negativos: dentre eles, o fato do Lederman Seven funcionar como uma tábua de mandamentos, o que leva professores e estudantes a "recitá-la como um mantra ou um catecismo" (MATTHEWS, 2012, p. 11, tradução nossa). Segundo ele, se a 
lista de Lederman é utilizada dessa forma, então todo o esforço para o ensino da NOS se perde.

Por exemplo, tomando o primeiro ponto do Lederman Seven - a natureza empírica do conhecimento científico, Lederman fica entre uma posição instrumentalista pragmática e empirista. Sim, pesquisa científica tem uma base empírica, mas a transcende mediante noções inventadas ou imaginadas. Na linha deste ponto de consenso e em vários outros da lista, Matthews (2012 p. 12, tradução nossa), fala também "do status ontológico das entidades da ciência": a ciência trabalha com entidades inobserváveis e, para isso, precisa usar uma perspectiva imaginativa. Vários exemplos dessa natureza podem ser levantados na ciência clássica: a ideia dos átomos, das ligações químicas, da esfera cristalina, que Aristóteles imaginava ser tão verdadeira que podia sustentar os planetas em suas órbitas, do flogisto, etc. Se há uma repetição, como afirma Matthews, desses itens da lista como uma espécie de mantra, não se pode afirmar que estudantes e professores estão bem informados sobre os aspectos da NOS, em especial no ponto que trata do papel da imaginação versus o papel da empiria na ciência. Decorre daí a dúvida em relação à posição filosófica de Lederman sobre a natureza das entidades teóricas. Além de que, sua lista não tem a sutileza suficiente para trazer detalhes educativamente valiosos sobre as concepções ontológicas mais adequadas em uma natureza da ciência escolar. As implicações dessas oscilações filosóficas são enormes para o ensino da NOS; por isso, acreditar que há listas de consenso, que há pontos canônicos nessas listas e, ainda pior, dogmatizar cada um dos pontos como mandamentos faz com que a formação na NOS fique definitivamente empobrecida ou deformada (MATTHEWS, 2012).

A partir da lista de consenso adotada pelos National Science Education Standards dos Estados Unidos (EUA) analisada por Douglas Allchin (ALLCHIN, 2013) e também mais oito dos maiores projetos curriculares dos EUA - que também utilizam as listas consensuais - pode-se depreender que a influência das listas consensuais da NOS nas reformas curriculares no âmbito do mundo anglo-saxão é notável. Segundo Allchin, juntamente com esses currículos dominados pelas listas consensuais, vem também o seu instrumento de avaliação mais conhecido, o Views of Nature of Science (VNOS) criado por Lederman et al. (2002), além de outras versões do mesmo instrumento publicadas posteriormente. Professores e estudantes de ciências estariam sob o estrito domínio das listas consensuais, instrumentalizadas no currículo e na avaliação. Mas, apesar de toda essa influência conquistada, as listas de consenso não devem ficar imunes às críticas, ao contrário, pois suas grandes influências requerem que os pesquisadores fiquem atentos para estabelecer críticas consistentes, que possam levar a reflexões profundas e criações de espaços para outras formas de entendimento do ensino da NOS, para além dessas listas de consenso.

Examinando dois pontos da lista dos National Science Education Standards: "a ciência é empírica" e "a ciência é influenciada por seu meio social e cultural", Allchin (2013, p. 13, tradução nossa) lança um importante questionamento: como conciliar essas duas afirmações? Até que ponto pode a ciência ser um empreendimento que está preso a uma empiria e, ao mesmo tempo, sofrer influências do meio social? Como professores e estudantes podem entender esses aspectos importantes da NOS, aparentemente contraditórios? E se estudantes e professores entenderem bem um dos pontos - a ciência é governada por experimentos e observações - em outro momento de sua formação em relação a NOS, eles aprenderem que valores e cultura influenciam a ciência? Como conciliar essas duas ideias de maneira epistemologicamente robusta? 
Outro par parcialmente contraditório aparece na mesma lista. Por um lado, a formação na NOS a partir dessa lista deve seguir a afirmação de que "a investigação é carregada de teoria". Por outro, deve reconciliar com a ideia de que cientistas são criativos. Ora, se são criativos não devem ficar tão amarrados às teorias estabelecidas: onde fica a margem para a inovação e a ruptura? Como formar na NOS dentro dessa aparente ambiguidade que sobrevém da vaga formulação das afirmações contidas nas listas consensuais? (ALLCHIN, 2013).

Para Allchin (2013), o problema de conviverem juntas na mesma lista afirmações que podem parecer contraditórias para estudantes ou professores, deve-se ao fato de que o caráter da lista seja o de justapor uma característica da NOS à outra, de forma pouco relacionada entre si e fortemente descontextualizada da história da ciência passada e presente, ou da necessidade de se referir a situações concretas, em particular. O caráter transcendente da ciência, que não se pode negociar, é sua contextualidade, ou melhor, sua riqueza contextual. A história da ciência nos ajuda a acessar esses contextos e casos particulares. Por exemplo, em dada situação, a criatividade do cientista para resolver um dilema em sua investigação pode ficar mais evidenciada do que seu compromisso com a teoria, ou vice-versa.

Aqui residiria o nó górdio das listas de consenso de NOS: são conjuntos de afirmações que, mesmo que tragam verdades parciais sobre que é a ciência, as apresentam descontextualizadas, sem sutilezas e com a pretensão de serem gerais. O ensino sobre a NOS não pode caminhar por mandatos; mesmo que esses mandatos sejam verdadeiros, são vistos de forma isolada e utilizados para responder a um determinado contexto ou caso particular. Allchin (2013) usa vários exemplos da ciência do passado e da atualidade para mostrar que apenas apontar em uma lista que a ciência é provisória não resolve o problema instaurado com os debates e as controvérsias no interior das comunidades científicas. Os criacionistas gostam da ideia de que a ciência seja provisória, embora não sejam melhores cientistas que os evolucionistas. $\mathrm{Na}$ briga da vacina, os que acreditaram que a vacina poderia causar autismo consideravam que a provisionalidade da ciência fosse desnecessária nesse caso. Um artigo, mesmo que tenha sido contradito posteriormente (o caso da vacina sobre a tríplice viral), será o suficiente para a formação de uma opinião final do cidadão comum. Já no caso do climategate, os que são contrários aos argumentos de que o aquecimento global tem causas antropogênicas clamam pela provisionalidade da ciência (ALLCHIN, 2013). Ou seja, aprender NOS significativamente exigiria pensar ou agir com ciência e sobre a ciência, revisar casos concretos, olhar as questões dentro de contextos e não somente seguir afirmações ditas consensuais que, de alguma maneira, traem a natureza filosófica da reflexão metacientífica, que estabelece um olhar crítico e coloca em dúvida verdades monolíticas.

\section{Whole Science}

Fazendo uma analogia com uma hipotética "comida integral", na qual não se economiza em nenhum ingrediente essencial, Allchin (2013) afirma que na Whole Science (ciência integral/ciência completa), da mesma forma, os professores e estudantes devem ter acesso ao que é fundamental em sua "dieta" pela compreensão da ciência e, por conseguinte, da própria NOS. Há aqui novamente uma crítica às listas altamente processadas, que na realidade não 
seriam saudáveis para uma compreensão crítica da NOS. Ciência integral ou completa implica uma soma de pelo menos dois aspectos inerentes dos processos científicos: os processos experimentais e conceituais da ciência, mais os processos sociais e culturais.

A força da expressão Whole Science deseja lembrar a todos os envolvidos no empreendimento científico, seja em sua construção, seja em sua divulgação ou ensino, que se trata de um esforço de congregação de características essenciais da ciência que devem fazer parte da nossa compreensão mais completa e holística da ciência como um todo.

Há também um problema com relação às diversas denominações ou às diversas formas como se tem concebido o tratamento da NOS. A partir de algumas características que um grupo de pesquisadores acredita ser essenciais na NOS, adota-se uma denominação particular. Então, há grupos que veem de forma adequada chamar a NOS de ciência como uma maneira de conhecer, ou como o conhecimento é construido, visão de mundo científica, práticas científicas, empreendimento científico, ou ainda como a ciência trabalha (ALLCHIN, 2017). Essa miríade de denominações da NOS traz subliminarmente a visão epistemológica de quem a nomeia de uma ou outra forma, ou seja, há na denominação um ressalto da forma de se aproximar epistemologicamente de certa característica da ciência que é eleita como principal, a despeito de outras. O resultado não é construtivo, segundo os adeptos da Whole Science, que enxergam que cada denominação carrega uma parte do que possa ser considerado essencial para caracterizar a ciência, de maneira que estaria em desacordo com uma visão mais sistêmica e integrada e que deveria, essencialmente, fazer parte de uma aproximação mais integral à ciência. Para a perspectiva da Whole Science, esses vários rótulos reduzem o conceito de ciência total ao tratar de forma distinta os três grandes motores da ciência: seu caráter experimental, seu aspecto conceitual e suas implicações sociais. Separam, portanto, o que em uma formação em NOS dentro da perspectiva Whole Science deveriam mais do que estar juntos, sobretudo se entendido pelo professor, estudante e cidadão comum, como processos que funcionam concatenados de maneira inexorável.

Não se pode entender a proposta de Allchin para a Whole Science completamente se não observarmos sua taxonomia da ciência proposta em seu livro. A ideia é dividir os processos de geração de conhecimento em etapas, e assim mostrar a importância da história da ciência, confiabilidade na ciência e as justificativas implícitas para a produção do conhecimento científico. Allchin apresenta então o "inventário parcial das dimensões de confiabilidade na ciência” (ALLCHIN, 2013, p. 24, tradução nossa). O inventário é constituído primordialmente por três dimensões: observacional, conceitual e sociocultural. $\mathrm{O}$ autor afirma que, à primeira vista, o inventário pode parecer longo e pesado, mas que, ao contrário das listas, é unificado e compacto. $\mathrm{Na}$ dimensão observacional, tem-se observação e medidas, experimentos e instrumentos. $\mathrm{Na}$ dimensão conceitual, padrões de raciocinio, dimensões históricas e dimensões humanas. Por fim, na dimensão sociocultural, têm-se as instituições, os vieses, o financiamento da pesquisa e a comunicação cientifica. Tem-se então, que, na visão da Whole Science, as partes que compõem a produção do conhecimento científico, grosso modo (ALLCHIN, 2013):

Nos modos empíricos de produção de dados e validação de dados. Aqui, há nuances interessantes para serem exploradas no ensino da NOS. Apenas como exemplos, a questão da ética em experimentos conduzidos com seres humanos, a análise estatística do erro e o papel de um estudo sistemático, em contrapartida com um estudo casual;

Em outra parte do empreendimento científico, Allchin indica em seu inventário a 
Bejarano, N. R. R.; Aduriz-Bravo, A.; Bonfim, C. S.

dimensão conceitual. Também a título de exemplos de aspectos da NOS que podem ser ensinados, tem-se a correlação versus causa, o papel das analogias e o pensamento interdisciplinar, e o espectro de motivações para se fazer ciência;

$\mathrm{Na}$ última, mas não menos importante, das dimensões propostas por Allchin, têm-se as influências socioculturais que afetam a produção científica e são afetadas por essa própria produção. Como exemplo de pontos da NOS que podem ser ensinados, buscando a alfabetização científica, destacam-se a liberdade acadêmica, o papel das crenças culturais (ideologia, religião, nacionalidade...), as fontes de financiamento e fraudes, e outras formas de má conduta na ciência.

No percurso de nossa revisão geral de fonte alternativas de NOS que se afastam da visão de consenso, interessa-nos aproximarmos das ideias de Allchin. Concordamos com sua visão acerca do uso limitado que as listas consensuais podem representar para o ensino da NOS quando usadas de forma descontextualizada e de forma excessivamente pragmática. Também nos alinhamos com sua proposta da Whole Science, que aponta três grandes dimensões do empreendimento científico e, dentro de cada uma dessas dimensões, propõe uma série de pontos que podem ser objetos de discussão em uma perspectiva de formação científica dentro da NOS. Acreditamos na ideia de que podemos utilizar a perspectiva da Whole Science nos processos de formação inicial de professores de ciências e de química, em particular.

\section{A natureza da ciência em Derek Hodson}

Podemos colocar as contribuições de Hodson (2009) fazendo parte dos esforços para estabelecer uma nova concepção de natureza da ciência afastada da visão de consenso e mais próxima da visão da Whole Science proposta por Allchin (2013). Ao concordar com estes dois autores, colocamo-nos em oposição à visão de consecução de listas e, por conseguinte, aos consensualistas do grupo de educadores científicos que acreditam que se possam apresentar as características centrais da ciência e de sua natureza através de uma lista pretensamente unificada. Assim, ensinar a NOS a partir de listas fechadas de consenso seria uma educação deletéria em termos do que seria mais adequado aprender sobre a natureza da ciência.

Em seu capítulo 7, denominado "Estrutura sintática da Ciência", Hodson (2009) discute especialmente a questão do método na ciência. Apresenta três grandes fases metodológicas: fase de planejamento, de ajuste das operações que coletarão os dados em uma perspectiva de exatidão (máxima possível) e confiabilidade (máxima possível); fase de reflexão, onde se coteja a teoria com os dados obtidos buscando alcançar explicações apoiadas em argumentos bem concatenados; e, finalmente, a fase de comunicação, onde se busca apresentar o relatório fidedigno das operações realizadas. Essa estrutura de fases se resultaria adequada para se organizar uma aula sobre o papel do método e sua relação com a teoria na ciência, embora, como adverte o autor, essas fases tenham pouco a dizer sobre o fazer científico, assim como ele se desenvolve naturalmente na prática.

Em uma formação em NOS na perspectiva Whole Science, temos que saber que esses passos não são estanques, tampouco mecânicos, sequenciais e imperativos. Enfim, para se ter uma ideia mais adequada da NOS envolvida na questão semântica (de sentidos) da ciência, devemos estar cientes de que, no curso de uma investigação científica, todos esses passos estão 
ligados e tudo pode, por razões contextuais da investigação, ser feito de maneira inovadora, desamarrado de esquemas pré-estabelecidos, de frente para trás ou tendo o desenvolvimento dessas fases feitas de maneira assimétrica, ou desembocando em outra investigação que não estava prevista a priori. Aqui residiria, de acordo com Hodson (2009), a dificuldade de se ensinar a NOS próximo do que ocorre em contextos reais de investigação.

Mas afinal, como devemos ensinar aspectos sintáticos da ciência para alunos e professores de ciências e para um público mais leigo? Inevitavelmente, temos que enfrentar o vaticínio de Feyerabend, conhecido como o anything goes (tudo vale). Parece que há um bom entendimento de que, para Feyerabend (2011), a ciência usa métodos, mas não tem um método. Feyerabend defende que a ciência faz uso de métodos e procedimentos variados (ad hoc, indutivismo, contraindução, hipotético, etc.). Porém, ela não adota em definitivo nem o método, nem um método. Logo, o anything goes apenas reflete essa postura que se funda, tal como em Kuhn (2011), em uma perspectiva histórica. Há que se ter um equilíbrio para se ensinar essa questão: se estudantes e professores de ciências aceitarem de maneira radical o vale tudo de Feyerabend, não estão entendendo bem como funciona a ciência em seu aspecto sintático. Porém, Hodson (2009) nos alerta de que um pouco de Feyerabend faz bem para se contextualizar os processos e procedimentos da investigação científica, no que se refere ao contexto de criação do processo científico.

Ao contrário, nos contextos de justificação, pouco ou quase nenhum Feyerabend é bem-vindo. Novamente, essa discussão apenas reafirma que tudo que desejamos ensinar em termos da NOS deve estar muito bem ancorado em um contexto concreto, em um caso específico de produção de conhecimento científico. Aprendizes da natureza da ciência devem entender o caráter provisório da ciência. No entanto, não podem imaginar que a ciência muda da noite para o dia.

Seria impossível expor aqui tudo o que na obra de Hodson interessa para uma boa formação em NOS. Pela falta de espaço, para efeitos desse estudo, vamos escolher mais alguns exemplos de sua visão que, insistimos, para nós, situa-se muito próximo da Whole Science e, ao mesmo tempo, distanciada em grande medida da ideia de formação em NOS, a partir de listas de consenso.

É bastante relevante que, para efeito de formação em NOS sobre como comunicar os resultados, o autor indica a importância do papel da argumentação. Alunos e professores de ciências, em suas aulas, devem se enfronhar em comunicar os resultados de suas investigações aprendendo que o mais importante é a construção de argumentos concatenados que consigam representar a investigação realizada e, ao mesmo tempo, convencer os possíveis leitores daqueles resultados (HODSON, 2009).

De acordo com Hodson (2009), a discussão do papel da experimentação nas salas de aula de ciências também se localiza no coração da formação em NOS. O trabalho de laboratório escolar - quando é realizado - está envolto em muitos mitos que precisam ser refletidos para um melhor entendimento dele dentro da formação da NOS. Um primeiro aspecto levantado por Hodson aponta para o caráter complexo da experimentação, ao contrário do que divulgam os livros didáticos. Rigorosamente, o experimento está atrelado à teoria, de maneira que "dados" não têm vida própria, como ingenuamente se pode supor. Nesse contexto, caem por terra os chamados testes cruciais (crucial experiments), a ilusão de que testes bem conduzidos levarão a 
resultados que poderiam ser vistos como certos, bem como o papel dos estudantes no trabalho experimental nas aulas de ciências. $\mathrm{O}$ autor aconselha que os estudantes, no contexto da experimentação, comportem-se menos como técnicos de laboratório e mais como cientistas criativos.

O entendimento da NOS relativo aos aspectos ligados à atividade experimental deve considerar que a complexidade dessa atividade deriva de suas imbricações com uma teoria (matriz teórica), com uma forma de procedimento na condução do experimento (matriz procedimental), que seriam os métodos aceitos pela comunidade em um determinado momento histórico e, por fim, com uma matriz instrumental que estaria ligada ao papel essencial dos instrumentos utilizados na investigação e de teorias subjacentes.

Há mais dois aspectos ainda ligados à questão da natureza teórico-experimental da ciência que podem suscitar discussões. Um deles se refere à visão de Hodson (2009) sobre o caráter de representação da realidade dos experimentos. Apoiado nas ideias do filósofo da ciência canadense Ian Hacking, Hodson defende que os experimentos são construídos e não passam de representações de parte da realidade. A justificativa é de que tudo em uma experimentação é altamente controlado, de maneira que diferem das condições que poderíamos chamar de reais. Se há uso de reagentes, os reagentes são puros para análise, se usa água ela é quase pura, bi ou tridestilada. Se há uso de plantas, as espécies utilizadas são as melhores geneticamente possíveis. E, seguindo essa argumentação, Hodson (2009), a exemplo de Hacking (1983), afirma que os experimentos são construções humanas. Sem dúvida, um aspecto complexo para que se possa ensinar aos professores e estudantes sobre qual a NOS presente nos experimentos. Os limites desse artigo impõem que não podemos tratar com mais profundidade outras discussões pontuadas por Hodson. De toda forma, clarificamos que ensinar NOS na linha da Whole Science a partir, principalmente, de Hodson e Allchin, é extremamente desafiador e complexo. Cada aspecto da ciência tem uma nuance, não há algo absoluto ou dogmático nessa visão. Com esse tipo de análise, fica evidente que as listas não cabem para uma formação em NOS que esteja em compasso com uma ideia de ciência sofisticada e contemporânea.

Hodson (2009) discute inúmeros outros aspectos da NOS. Sua estrutura substantiva, que trata sobre os conteúdos duros, as teorias e todos seus aspectos formais. Da mesma forma que discute sobre a questão do método na ciência, quando explana acerca do corpo teórico da ciência, ele o faz sem fechar questão. Um aspecto sobre os conteúdos da ciência na formação sobre a NOS: em uma perspectiva de busca pela alfabetização científica, é preciso refletir de maneira explícita sobre os processos de pensamento que os cientistas usam para produzir conhecimento científico. Tal reflexão pode ajudar a entender o aprendizado dos estudantes sobre conteúdos científicos. Outro aspecto ligado aos conteúdos é quanto podemos avançar com os estudantes na compreensão da dimensão das injunções socioculturais junto à produção do conhecimento científico. Ou seja, quais são as condições sociais, culturais, políticas e econômicas que levam à adoção de uma teoria particular, ou sua rejeição. Quer dizer, a discussão sobre a influência social que sofre a ciência (HODSON, 2009).

Devemos lembrar que, na visão Whole Science, o mais importante é pensar a natureza da ciência em seus vários matizes e, se for possível, através de casos concretos e exemplos reais. Fazer do ensino de ciências e de sua natureza um exercício de busca por uma simulação da atividade científica que tente ser a mais autêntica e verdadeira possível. Assim, surgem situações contextualizadas que permitem que se discutam aspectos da NOS que são essenciais para uma 
formação epistemológica adequada e sem deformações.

Além da introdução dessa ideia de uma aproximação integral, a natureza da ciência, consideramos também, não pode prescindir da discussão da história e filosofia das ciências para entender o funcionamento do empreendimento científico. Aprofundaremos essa proposta em seguida.

\section{Exemplo para aplicação da Whole Science em contexto da história da Química}

Julgamos que a visão de Allchin (2013), compartilhada em linhas gerais por Hodson (2009), seja uma alternativa mais adequada que a ideia das listas. Assim, a chamada Whole Science se contrapõe às ideias das listas consensuais em várias frentes que precisam ser esclarecidas. Em primeiro lugar, não se deve escamotear que a normatividade, extremamente presente nas listas consensuais, estejam presentes - em muito menor grau - também na proposta de Douglas Allchin (ALLCHIN, 2013, 2017). Ressaltar características da ciência, em detrimento de outras, sempre se pode levar ao risco de se estar sendo mais ou menos normativo. Porém, quanto a isso, não há como contornar de forma a agradar a todos os pesquisadores. A vantagem da Whole Science é que essa abordagem vai colocar as características escolhidas da ciência em situação contextual. Ora, estamos apostando que a HPS é uma opção teórica e metodológica, por várias razões já explicitadas no texto, mas principalmente porque entende a melhoria do ensino de ciências quando informado pela História, Filosofia e Sociologia das Ciências, ou seja, de maneira contextual. De forma coerente e natural, também temos que apoiar o ensino da NOS, feito a partir de uma abordagem contextual e não através de listas. Tudo nos leva a crer que haverá maior entendimento da NOS, quando se tomar suas características colocadas em contextos concretos de utilização no cotidiano da construção da ciência, feito de forma explícita. Trazemos aqui um pequeno fragmento histórico, retirado da história da Química, que buscará exemplificar o uso da NOS de forma contextual na linha apregoada por Allchin.

Vamos propor a discussão de parte de uma história fictícia, descrita no livro Oxigênio, escrito por Roald Hoffmann e Carl Djerassi em 2004. Hoffmann é um Nobel de Química de 1981 que até como consultor ad hoc carnavalesco brasileiro já atuou. Djerassi, um grande cientista e inventor da pílula anticoncepcional, tinha grande consciência das ideias pré-concebidas que se tem sobre o que é um cientista e sobre como se pensa a construção do conhecimento científico. Em sua biografia publicada em 1992, disse que discordava que os cientistas eram "superespecialistas", "enclausurados em seus laboratórios", "comunicando-se em linguagem incompreensível” e "alienados dos problemas cotidianos" (DJERASSI, 1992). Em vez dessa imagem, o autor entende os cientistas como "curiosos", "autocentrados, imperfeitos", "atuando em qualquer ambiente intelectual" e "passíveis de se envolverem em quaisquer questões sociais candentes".

Assim, acreditamos que a ficção escrita por esses dois cientistas atende nossa necessidade de contextualizar aspectos da NOS. Ao buscar referências sobre o livro de Hoffmann e Djerassi (2004) encontramos um artigo que acabou sendo importante para os nossos objetivos de destacar do livro aspectos da NOS que poderiam potencialmente serem utilizados para efeito de compreensão da natureza da ciência, o artigo de Moreira (2012). Desse artigo 
extraímos os aspectos que apontam para os comportamentos dos cientistas descritos no livro, que poderiam servir para compor uma agenda de discussões da NOS, na perspectiva da ciência integral. O artigo usa uma análise baseada em Foucault. Não nos preocupamos com essa abordagem teórica, apenas com os excertos destacados para a análise, que a nosso juízo servem aos propósitos pretendidos.

\section{Quem descobriu o oxigênio? O uso da Whole Science para se ensinar NOS}

Lavoisier, Priestley e Scheele confundiram a ciência do século XVIII ao descobrirem quase simultaneamente a existência do gás oxigênio, como relatado por Hoffmann e Djerassi (2004). Em seu textos, os autores propõem uma volta ao passado para tentar solucionar esse enigma da primazia do descobrimento do gás vital. Com um adendo prosaico: a comissão do Nobel é que vai chancelar a autoria da descoberta e laurear o descobridor com o Nobel de Química. Logo, o texto é quase histórico e ficcional, apenas para dizer que o propósito de inserção da história da ciência, por exemplo, pode ser perseguido de várias maneiras, inclusive em uma delas onde a história pode ser levemente falseada para ganhar fluidez (PESSOA JR., 1996).

Há personagens do ano de 1777, especialmente os cientistas e suas respectivas esposas, Lavoisier e Madame Lavoisier, Priestley e sua esposa Mary Priestley, Scheele e Sara Pohl. Há, obviamente, os personagens da contemporaneidade (localizados no ano de 2001). Notadamente, pesquisadores ligados ao comitê do Nobel de Química que entram em um túnel do tempo e viajam até o centro da controvérsia histórica, localizada três séculos atrás.

O escrutínio que se segue buscando atribuir o prêmio Nobel ao descobridor verdadeiro do oxigênio busca utilizar argumentos racionais para fazer a escolha do ganhador. Nessa busca, entram em cena aspectos como a preocupação de cada um dos três cientistas frente ao trabalho científico, mas também quanto às suas preocupações com a humanidade. Tanto os cientistas do passado quanto os do presente são questionados sobre suas práticas científicas aliadas às suas motivações, que os levam por esses caminhos da descoberta de novos conhecimentos (MOREIRA, 2012). Vejam que até aqui há vários aspectos da NOS que estão sendo postos para discussão: preocupação com a humanidade (poderia ser algo como relação da sociedade com a ciência e da ciência com a sociedade), prática científica (aqui podem ser discutidos vários aspectos ligados à prática, tais como a ética na produção e análise de dados, a ética na comunicação, enfim...). Já na comitiva do Nobel, os cientistas também expõem suas fraquezas e humanidades não muito afinadas com a visão comum do cientista ideal. Em algum momento do trabalho, um dos cientistas do comitê sugere que escolher uma pessoa que de qualquer sorte estaria morta, diante do imponderável da ficção, seria uma "perda de tempo", já que o "morto" não poderia "trocar favores" (MOREIRA, 2012). Seria esta prática, a de dádiva e contradádiva, uma prática usual no interior do cotidiano científico?

Fatores como relacionamentos pessoais tensos, disputa por obtenção de verbas para a pesquisa utilizando poder pessoal e influência, troca de favores nem sempre louváveis, são legitimamente outros aspectos da NOS que podem ser evidenciados a partir deste texto. Esses aspectos também servem para conferir um grau de "humanidade" aos cientistas que raramente 
se leva em conta. Cientistas podem também ser ambiciosos, quando se trata de obtenção de recursos para suas pesquisas e ocupação de postos de poder nas instituições científicas. Há um momento em que os pesquisadores do Nobel chegam a duvidar que cientistas do sec. XVIII poderiam ser tão gananciosos como os de hoje (MOREIRA, 2012). Esquecem que sem dinheiro não se faz ciência, seja em qualquer tempo. A busca por recursos pode ser uma corrida limpa ou com esbarrões ou tropeções propositais. Aqui, novamente entra a ética na busca pelo financiamento da pesquisa e também entra em cena uma ética humana que vale para todos: cientistas ou não. Afinal, a mulher e o homem comuns também precisam se guiar pela ética em suas ações cotidianas. Ou seja, a chamada ambição deve ser controlada. Se a ambição é desmedida, tudo mais se perde. Esse é mais um ponto genuíno de discussão sobre a NOS. Fica também a questão que pode ser debatida no contexto do ensino da NOS: ambição é um atributo que todos os bons cientistas devem ter? Quem modula a ambição do cientista? Sem ambição não se pode ser um bom cientista? Ligando essa questão da ambição com a ideia de motivação para se fazer ciência, levantada no início do trabalho da comissão, vê-se que ter exclusivamente a ambição como motivação pode não ser um bom caminho.

Outros valores precisam ser sobrepesados. Novamente, um excelente ponto para a discussão de aspectos da NOS. A ideia aqui não é esgotar todos os pontos do livro que são passíveis de serem utilizados para a discussão da NOS. No entanto, tendo sido escrito por dois cientistas da mais alta conta como Roald Hoffmann e Carl Djerassi, devemos prestar bastante atenção às polêmicas que trazem à mesa para discussão sobre como se comportam os cientistas ao fazerem ciência. Parece-nos que, no centro da discussão do livro - seja entre os cientistas do passado, seja entre os cientistas do Nobel - está a questão da ética. Apesar de a ciência nazista ter em seus quadros os maiores cientistas da época, especialmente físicos e químicos, não se pode aceitar a ciência produzida pelos nazistas. Simplesmente porque ela foi produzida sem ética, ou com a ética nazista, o que é pior. Assim, propomos a utilização desse pequeno livro de Hoffmann e Djerassi (2004) como uma boa opção de utilização para efeito de discussão de aspectos da NOS na perspectiva da Whole Science ou Ciência Integral, como apregoa Allchin (2013).

\section{Considerações finais}

Este estudo teve como objetivo discutir a importância da natureza da ciência na formação dos professores de ciências e no ensino de ciências, em geral. Os debates acerca da NOS evidenciam a crescente ascensão desse campo. Muitos pesquisadores defendem, embora haja divergências epistemológicas, a NOS como perspectiva teórica em diferentes níveis educacionais. Fizemos um regaste histórico, salientando figuras consideradas emblemáticas para o empreendimento da NOS como Willian Whewell, James B. Conant e o próprio Michael R. Matthews, na atualidade, que comprovam tal ascensão. Há certo consenso na assunção de que saber sobre a ciência é tão importante quanto saber conteúdos de ciência. Assim, um indivíduo cientificamente alfabetizado não é somente alguém que sabe conteúdos da ciência, mas também e, sobretudo, que conhece a natureza da ciência. Em virtude disso, fomentar uma educação científica por meio da NOS pode contribuir de forma significativa com o ensino de 
ciências.

Ilustramos perspectivas conhecidas na literatura (Consensus View e Whole Science) no sentido de reforçar a abordagem proposta por Douglas Allchin (ALLCHIN, 2013, 2017) e salientar, ao mesmo tempo, as fragilidades em torno das listas consensuais. Fazendo uma comparação entre o inventário parcial proposto por Allchin e as listas consensuais, por exemplo, vê-se que na dimensão conceitual também há pontos de ligação com as listas. Se na dimensão conceitual se fala em "dimensões humanas", as listas apontam para "criatividade do cientista", "influência da sociedade e da cultura" sobre a ciência. Há uma correspondência entre as listas e a proposta de Allchin. Afinal, estão falando da mesma coisa: a Ciência, porém, de maneiras bem diferentes. Nas listas, de forma canônica, inflexível, desconectadas e descontextualizada (como reafirmamos várias vezes aqui). Em Allchin (2013) colocam-se os pontos dos cânones dentro de contextos históricos, de maneira flexível e, portanto, contextualizados. Alguns pontos das dimensões estão mais reafirmados do que nas listas, como a ideia de financiamento de pesquisa e de possíveis enviesamentos na condução das pesquisas. É um problema mais de ênfase do que de inexistência de contato entre as listas e a proposta de Allchin. Assumimos que, apesar de a Whole Science apresentar certo caráter normativo, esta característica é ainda mais evidente nas listas consensuais, que lidam com uma ciência genérica, abstrata e fora de contexto.

Levantamos argumentos com base em Douglas Allchin e em Derek Hodson em torno da NOS, no âmbito de suportar a Whole Science como contraponto às listas. Allchin (2017) afirma que a Whole Science promove uma educação científica funcional e contextual, o que está de acordo com os documentos curriculares internacionais. Encontramos em Hodson (2009) justificativas que corroboram para o ensino de ciências, aglutinados sob a noção de NOS na perspectiva da $W$ hole Science, pois este deve estar muito bem ancorado em um contexto concreto, em um caso específico de produção de conhecimento científico. Por fim, demonstramos, por meio de um exemplo, o uso da Whole Science, sob a forma de uma história ficcional, na qual vários pontos da natureza da ciência podem ser explorados com o propósito de seu ensino.

\section{Referências}

ALLCHIN, D. Beyond the consensus view: whole science. Canadian Journal of Science, Mathematics and Technology Education, Toronto, v. 17, n. 1, p. 18-26, 2017.

ALLCHIN, D. Teaching the nature of science: perspectives \& resources. Saint Paul: SHiPS Education Press, 2013.

ABD-EL-KHALICK, F.; BELL, R. L.; LEDERMAN, N. G. The nature of science and instructional practice: making the unnatural natural. Science Education, New York, v. 82, n. 4, p. 417-436, 1998.

CLOUGH, M. Teaching the nature of science to secondary and post-secondary students: questions rather than tenets. The Pantaneto Forum, Borehamwood, v. 25, p. 31-40, 2007.

CONANT, J. B.; NASH, K. L.; ROLLER, D.; ROLLER, D. H. D. Harvard case histories in experimental science. Cambridge: Harvard University Press, 1957. 
DJERASSI, C. The pill, pygmy chimps, and Degas' horse. New York: Basic Books, 1992. FERNÁNDEZ, I.; GIL, D.; CARRASCOSA, J.; CACHAPUZ, A.; PRAIA, J. F. Visiones deformadas de la ciencia transmitidas por la enseñanza. Enseñanza de las Ciencias, Barcelona, v. 20, n. 3, p. 477-488, 2002.

FEYERABEND, P. Contra o método. 2. ed. São Paulo: Editora Unesp, 2011.

HACKING, I. Representing and intervening. Cambridge: Cambridge University Press, 1983.

HODSON, D. Teaching and learning about science: language, theories, methods, history, traditions and values. Boston: Sense Publishers, 2009.

HOFFMAN, R.; DJERASSI, C. Oxigênio. Rio de Janeiro: Vieira \& Lent, 2004.

KUHN, T. S. A. Estrutura das revoluções científicas. 11. ed. São Paulo: Perspectiva, 2011.

LEDERMAN, N. G. Students' and teachers' conceptions of the nature of science: a review of the research. Journal of Research in Science Teaching, New York, v. 29, n. 4, p. 331-359, 1992.

LEDERMAN, N. G. Syntax of nature of science within inquiry and science instruction. In: FLICK, L. B.; LEDERMAN, N. G. (org.). Scientific inquiry and nature of science. Dordrecht: Springer, 2004. p. 301-317.

LEDERMAN, N. G.; ABD-EL-KHALICK, F.; BELL, R. L.; SCHWARTZ, R. S. Views of nature of science questionnaire: toward valid and meaningful assessment of learners' conceptions of nature of science. Journal of Research in Science Teaching, New York, v. 39, n. 6, p. 331-359, 2002.

MCCOMAS, W. F.; OLSON, J. The nature of science in international science education standards documents. In: MCCOMAS, W. F. (org.). Nature of science in science education: rationales and strategies. Dordrecht: Kluwer, 1998. p. 41-52.

MARÍN, N.; BENARROCH, M. N.; NIAZ, M. Revisión de consensos sobre naturaleza de la ciencia. Revista de Educación, Madrid, n. 361, p. 117-140, 2013. DOI: https://doi. org/10.4438/1988-592X-RE-2011-361-137.

MATTHEWS, M. Changing the focus: from nature of science to feature of science. In: KHINE, M. S. (org.). Advances in nature of science research. Dordrecht: Springer, 2012. p. 3-26.

MOREIRA, L. M. Oxigênio: uma abordagem filosófica visando discussões acerca da educação em ciências - parte 1: poder e ambição. Ciência \& Educação, Bauru, v. 18, n. 4, p. 363-381, 2012. DOI: https://doi.org/10.1590/S1516-73132012000400005.

OSBORNE, J. F.; COLLINS, S.; RATCLIFFE, M.; MILLAR, R.; DUSCHL, R. What "ideasabout-science" should be taught in school science?: a Delphi study of the expert community. Journal of Research in Science Teaching, New York, v. 40, n. 7, p. 692-720, 2003. 
Bejarano, N. R. R.; Aduriz-Bravo, A.; Bonfim, C. S.

PESSOA JR., O. Quando a abordagem histórica deve ser usada no ensino de ciências?

Ciência \& Ensino, Piracicaba, n. 1, p. 4-6, 1996.

VÁZQUEZ, A.; ACEVEDO, J. A.; MANASSERO, M. A; ACEVEDO, P. Cuatro paradigmas básicos sobre la naturaleza de la ciencia. Argumentos de Razón Técnica, Sevilha, n. 4, p. 135-176, 2001.

VÁZQUEZ-ALONZO, A.; MANASSERO-MAS, M. A.; ACEVEDO-DÍAZ, J. A.;

ACEVEDO-ROMERO, P. Consensos sobre a natureza da ciência: a ciência e a tecnologia na sociedade. Química Nova na Escola, São Paulo, n. 27, p. 34-50, 2008. 